Preparing Drosophila for Tissue Processing

Connie McManus, Utah State University conmac@cc.usu.edu

All insects have an exoskeleton made of chitin, which is a protein that is hard and impervious to moisture. To enable processing reagents to more effectively enter the body cavity, a small slit in the abdomen can be made. For very small insects, such as the fruit fly, Drosophila, micro dissecting tools can be made from commonly found items such as insulated electrical wire, double edged razor blades and wood applicator sticks.

\section{MAKING THE MICRO SCALPEL}

1) Using a single edged razor blade, make a slit approximately $1 \mathrm{~mm}$ parallel with the length in one end a wood applicator stick.
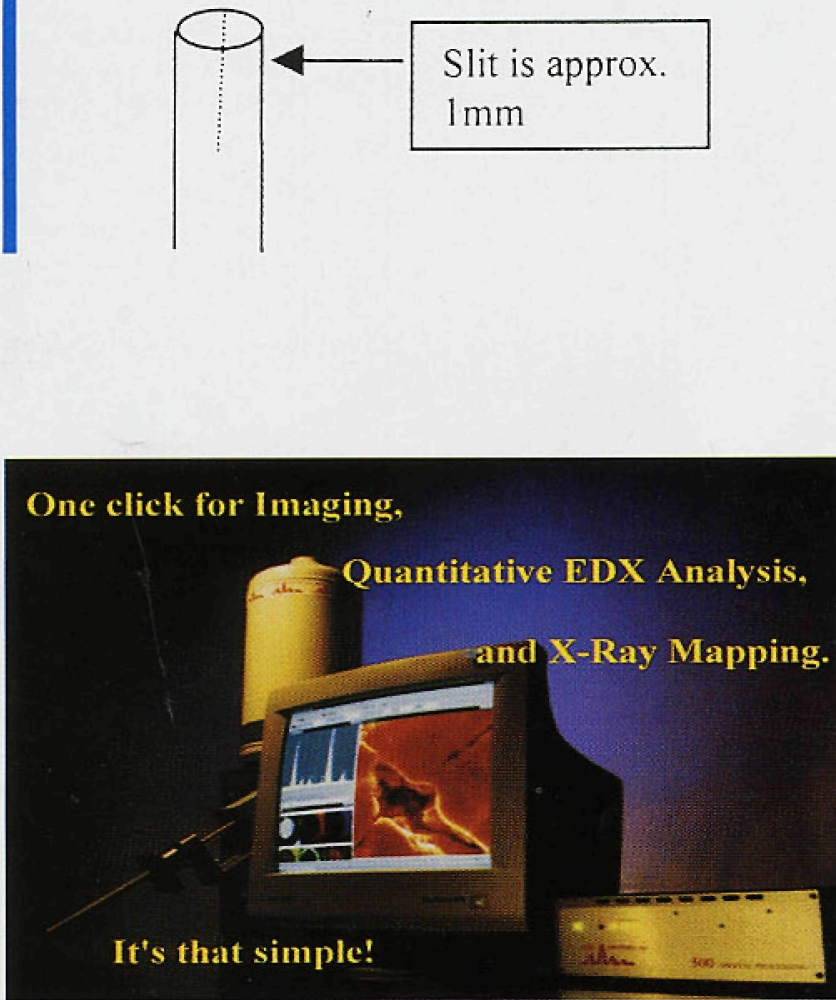

Digital Pulse Processing Electronics

High-Resolution Light-Element Si(Li) Detectors High-Resolution Digital Imaging

Accurate and Fast Quantitative Analysis

Position-Indexed Spectroscopy

Automatic and Customized Particle/Feature Analysis Free Software Updates

Excellent Technical Support

Best Price/Performance Ratio in the Industry

Did we miss something? EXIF $\triangle$ SXSTEMS

IXRF Systems, Inc.

15715 Brookford Drive

Houston, TX 77059

Tel: (281) 286-6485 Fax: (281) 286-2660 http://www.ixrfsystems.com
2) Use the single edged razor blade to flatten the tip of the applicator stick on both sides of the slit.

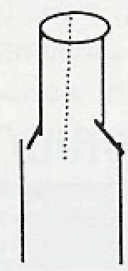

3) Break off a 2-3 $\mathrm{mm}$ wedge from the edge of a double edged razor. Cover the razor's edge with the paper wrapping and snap off the wedge with a pair of pliers. One end should be sharp and pointed, the other end dull and flat

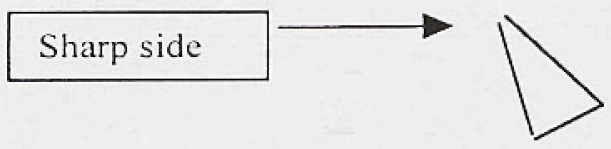

4) Put one drop of cyanocryolate glue on the flat, dull end and insert into the slit in the wood applicator stick. Be sure it is firmly seated in the slit.

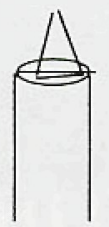

5) Wrap the end with wire. You can obtain the wire from a piece of electrical wire. Remove the plastic insulating coat using a pair of electrician's cutters. Unwind the bundle of Copper wires and use a $5 \mathrm{~cm}$ length of one of these copper wires. Wrap the wire tightly around the flattened end of the applicator stick so the wire is only one layer thick. Cut off any length of wire that is left over at the end. It is important not overlap the wire as this will make it cumbersome to use.

6) Seal the wire by melting dental wax over it or spreading cyanocryolate glue over the entire circumference.

\section{DISSECTING THE INSECT}

1) Kill the insects in $\mathrm{CO} 2$ gas or freeze. Then one at a time put the insect on double sided adhesive tape (made by $3 \mathrm{M}$ Company). Use a pair of fine tipped forceps and handle them gently. This will hold the insect in place while you work.

2) Stick the insect on a glass petri dish and place under a dissecting microscope. Sometimes it helps to cover the insect with boiled DI water or PBS while you work.

3) Use the micro scalpel to make an opening in the abdomen of the insect. Be careful to cut only the chitinous outer layer and not damage any of the internal structures. This becomes easier to do with much practice.

4) If PBS or boiled DI water was used, pour it off and begin processing according to your protocol. The adhesive will dissolve in alcohol and the cellophane can be plucked out with forceps.

This method also works very well if you need to dissect out parts of the insect. In this case, I have used dental wax (also called sticky wax) to hold the insect rather than double sided adhesive tape as this gives more support for dissections. 


\section{Improve Your VPSEM}

Secondary Imaging Performance With....

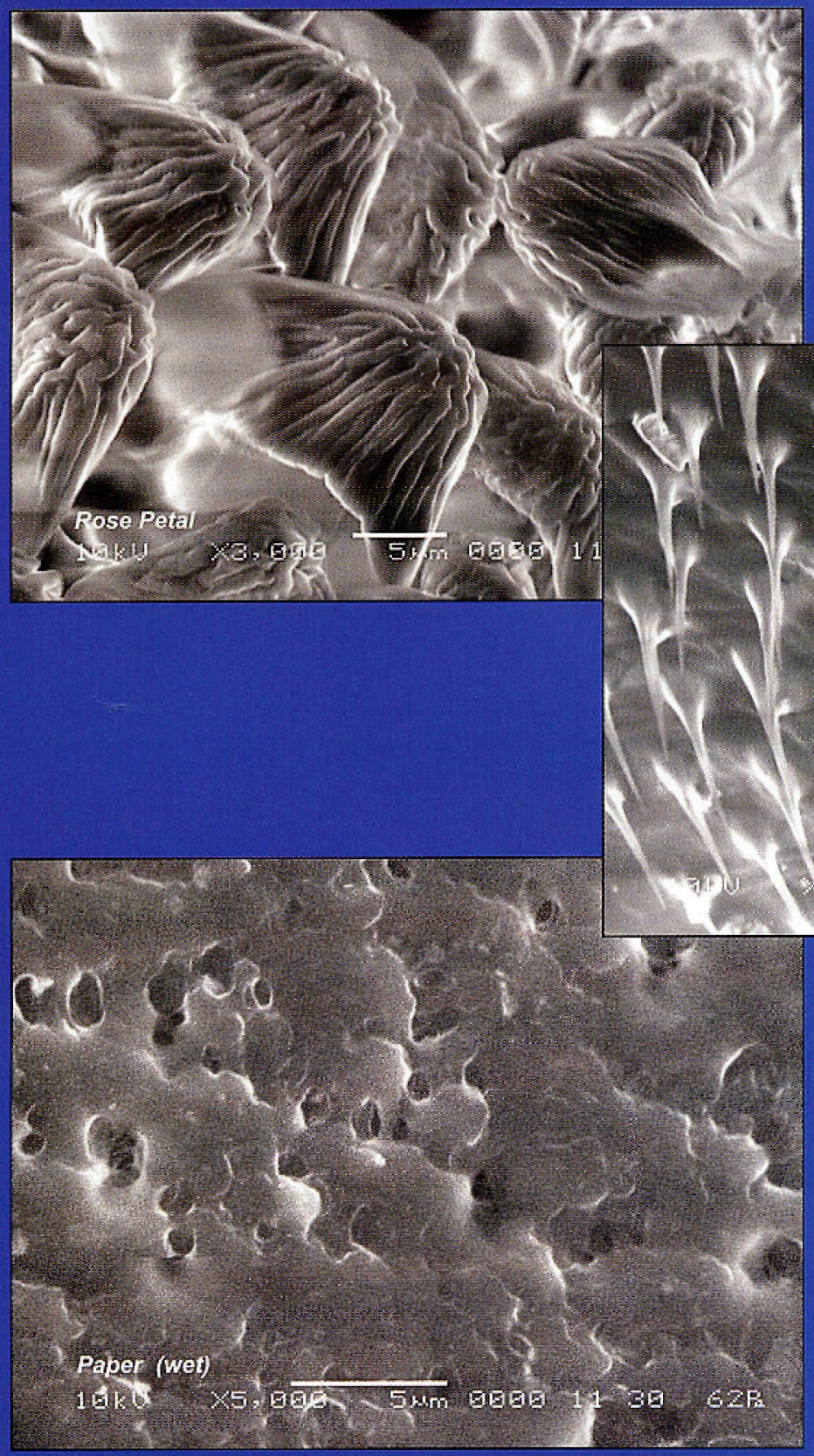

At last-Secondary Electron Imaging for your VPSEM! AMT's new MAXSEM Detector will enhance the performance of your new or existing instrument.

a a lasect Leg

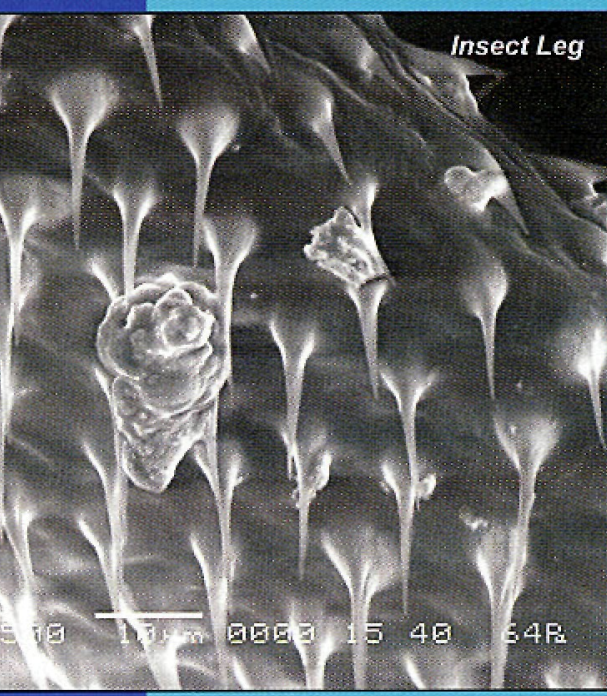

High Sensitivity

Rapid Scan Rates

Retrofittable To All SEMs

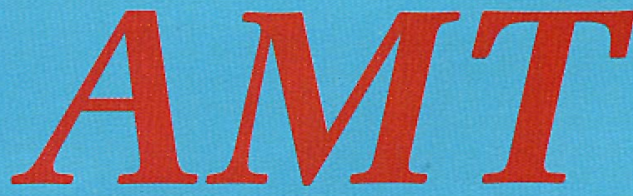

Advanced Microscopy Techniques 3 Electronics Avenue Danvers, MA 01923 Tel: (978)774-5550 Fax: (978)739-4313 Email: amtcorp@delphi.com http://www.msa.microscopy.com/ - amt/ 